\title{
Manufacturing of Composite Pasta by a Mixing Plan
}

\author{
Laurette Brigelia Nkeletela1, Fanny Belgonde Ganongo-Po1,2, André Kimbonguila1,2, \\ Salomé Itoua Guenonie1, Louis Matos ${ }^{1}$, Jeremy Petit ${ }^{2}$, Joel Scher ${ }^{2}$, Jean Mathurin Nzikou1,3* \\ ${ }^{1}$ Engineering Laboratories of Industrial Processes, ENSP, Marien Ngouabi University, Brazzaville, Republic of the Congo \\ ${ }^{2}$ University of Lorraine, LIBio (Laboratory of Biomolecules Engineering), Nancy, France \\ ${ }^{3}$ Institute for Medicinal Research, Center for Research and Study, Djibouti, Republic of Djibouti \\ Email: ^nzikoumath@gmail.com
}

How to cite this paper: Nkeletela, L.B., Ganongo-Po, F.B., Kimbonguila, A., Guenonie, S.I., Matos, L., Petit, J., Scher, J. and Nzikou, J.M. (2021) Manufacturing of Composite Pasta by a Mixing Plan. Food and Nutrition Sciences, 12, 206-221.

https://doi.org/10.4236/fns.2021.122017

Received: December 8, 2020

Accepted: February 23, 2021

Published: February 26, 2021

Copyright (c) 2021 by author(s) and Scientific Research Publishing Inc. This work is licensed under the Creative Commons Attribution International License (CC BY 4.0).

http://creativecommons.org/licenses/by/4.0/

\section{Open Access}

\begin{abstract}
The partial replacement of durum wheat semolina with local flours such as soybeans and yam reduces the dependence of durum wheat semolina for the production of pasta. The main objective of this study is to develop yam flour (A) from Dioscorea alata in the manufacture of pasta made with durum wheat semolina (B) and soy flour (C) (raw materials). The methodology adopted consists first of all in the characterization of yam, soybean and durum wheat semolina. An experimental design was developed to bring out the balanced mixing plan in well-defined proportions with ten (10) tests. Chemical and functional analyzes were carried out on the pastes obtained from these formulations. The functional properties allowed us to determine the optimal mixing plan using a mathematical model. The sensory properties of the optimal compound dough were estimated in comparison with the control doughs. The results on the chemical properties of raw materials A, B and C obtained on the water content vary from $10.29 \%$ to $12.29 \%$; those of ashes vary from $0.91 \%$ to $5.74 \%$ and those of proteins vary from $3.24 \%$ to $20.17 \%$. The results of the chemical and functional parameters of compound pasta gave very diverse values. We find that the water content, the ash content, the protein content and the acidity rate of the series of 10 tests are respectively from $6.60 \%$ to $14.97 \%$, from $0.97 \%$ to $1.67 \%$, from $7.15 \%$ to $12.10 \%$ and from $1.35 \%$ to $3.60 \%$. Regarding the optimal cooking time for this series of 10 tests, it varies from $15 \mathrm{~min}$ to $20 \mathrm{~min}$ with a swelling index which is between $59.70 \%$ and $107.12 \%$. Statistical tests (test F) from the different models indicate that the main regression effects are not significant with a p-value probability greater than 0.05 . The models obtained were significant with a good value for the coefficient of determination $\mathrm{R}^{2}$. The sensory test approved that optimal compound pasta has good overall acceptability compared to $100 \%$
\end{abstract}


durum wheat pasta. The $20.40 \%$ yam flour mixture $(102.020 \mathrm{~g})$; $55.19 \%$ of durum wheat semolina $(275.982 \mathrm{~g})$ and $24.39 \%$ of soy flour $(121.998 \mathrm{~g})$ has good potential in the preparation of compound pasta.

\section{Keywords}

Compound Pasta, Chemical and Functional Parameters, Optimization, Sensory Test

\section{Introduction}

Pasta in Congo Brazzaville is becoming more and more a food habit of most Congolese. Its consumption has become commonplace in our country because they are universally consumed and appreciated by the simplicity of their manufacture, their ease of transport, their excellent suitability for conservation, their good nutritional and hygienic quality. By-products in a food that is easy to prepare and economically more profitable today affect a large part of the population whose reasons for their use depend on many factors [1]. Today, the partial replacement of flour of durum wheat by locally produced flours has become common, especially in countries importing durum wheat. However, various studies have already been conducted by [2] [3] [4], and have shown the benefits using other flours and powders as a nutritional supplement to durum wheat flour for making and obtaining pasta with a balanced nutritional value. However, maintaining the chemical, functional and sensory properties of pasta could be a big challenge. To meet this challenge, the method of experimental designs has been adopted, these are techniques which make it possible to quantify the effects of various factors on responses and to optimize them in well-defined experimental areas. The main objective of this study is to develop yam flour in the production of pasta made with durum wheat semolina and soy flour. To achieve this main objective, this work gives the following sub-objectives: the evaluation and modeling of the effects of compound pasta on chemical and functional properties by the development of polynomial regression equations using the methodology of blueprints experiments, the optimization of functional properties using the multi-criteria optimization method (desirability) to obtain the optimal mixture and finally the evaluation of the sensory properties of compound pasta made from the optimal mixture and compare them to the $100 \%$ durum wheat semolina.

\section{Material and Methods}

\subsection{Plant Material}

We used three (3) types of products for the formulation of pasta among which:

- Yam flour was produced from the white variety "Ngumvu as vernacular name" of the Dioscorea alata L. yam from the Madingou districk in Congo 
Brazzaville. The tubers were calibrated using a caliper, washed with tap water, peeled and cut into slices $0.5 \mathrm{~cm}$ thick, $4 \mathrm{~cm}$ in length and $3 \mathrm{~cm}$ in width using a stainless steel knife and a graduated ruler. The slices were washed again with clean water to remove a lot of glutinous material. They were then bleached at $90^{\circ} \mathrm{C}$ for one minute to inactivate the enzymes. After that, the previously blanched yam slices were dried at $60^{\circ} \mathrm{C}$ for 24 hours, ground (using a German type RETSH MULHE grinder) and sieved using a $125 \mu \mathrm{m}$ mesh sieve. The flour obtained was finally stored in polyethylene bags before mixing.

- The fine durum wheat semolina of superior quality produced by Belle France and wrapped in plastic films and stored in a dry place at room temperature was bought in a supermarket Casino.

- The soy flour was bought at the organic health establishment located at the Moungali roundabout.

The three products are part of our raw materials: yam flour $(\mathrm{A})$, durum wheat semolina (B) and soy flour (C).

\subsection{Preparation of Flour}

The yam, durum wheat semolina and soy flour were mixed using a whisk in a stainless steel bowl to form 10 samples of flour composed in different proportions according to the centered mixing plan (Table 1) and stored in airtight containers before making the composite pasta.

\subsection{Experiment Plan and Statistical Analysis}

The mixing plan test matrix is presented in Table 1 . Minitab version 17 software was used to carry out the mixing plan and analyze the results obtained. Mixing plans (centered plans, lattice simplex plans, optimal plans) designed especially

Table 1. Matrix of tests of the centered mixing plan.

\begin{tabular}{cccc}
\hline Ordre d'essai & A (g) & B (g) & C(g) \\
\hline 1 & 133.33 & 233.33 & 133.33 \\
2 & 200.00 & 100.00 & 200.00 \\
3 & 100.00 & 300.00 & 100.00 \\
4 & 166.67 & 166.67 & 166.67 \\
5 & 133.33 & 133.33 & 233.33 \\
6 & 100.00 & 100.00 & 300.00 \\
7 & 300.00 & 100.00 & 100.00 \\
8 & 100.00 & 200.00 & 200.00 \\
9 & 233.33 & 133.33 & 133.33 \\
10 & 200.00 & 200.00 & 100.00 \\
\hline
\end{tabular}

A: yam flour, B: durum wheat semolina, C: soy flour. 
for mixtures of constituents.

These constituents are not independent of each other. Their sum must always be $100 \%$ or per unit. The answers depend on the proportion of each constituent. The focused plan for studying three components includes: (i) Pure products; (ii) Mixtures half-half of two pure products, (iii) The mixture containing one third of each pure product (central point) [5]. In our study, the mixing plan centered on 03 components was adopted to determine the optimal formulation of the compound flour used in the manufacture of optimal pasta. The (controlled) variables are yam (A), durum wheat (B) and soy flour (C), and the answers are chemical parameters: water content, ash, protein, acidity level and functional parameters: Optimal Cooking Time (OCT) and Swelling Index (GI). The significant factors (probability less than 5\%) were determined by performing an analysis of variance (ANOVA) on the experimental results obtained.

In our study we have:

$$
100 \leq \text { A: yam flour } \geq 300
$$

$100 \leq$ B: durum wheat semolina $\geq 300$

$$
\begin{gathered}
100 \leq \text { C: soy flour } \geq 300 \\
\text { A }+B+C=500
\end{gathered}
$$

\subsection{Pastification Test (Production of Pasta)}

For the production of pasta, we adopted the following manufacturing process: The ingredients (yam and soy flour, durum wheat semolina, salt and water) were kneaded in a stainless steel bowl and leave rest for 15 minutes to allow the constituents of the dough to be homogeneously hydrated. Manual kneading was then carried out for 10 minutes to obtain a coherent, non-sticky dough with good malleability. The dough is then divided into 4 and covered with plastic film to prevent the dough from drying out. These dough pieces were rolled into thin sheets using a rolling mill intended for the production of essential type $b$ pasta and cut into ribbons with the cookie cutter attached to the rolling mill (cutting section at $3 \mathrm{~mm}$ width) and then dried to the oven at $40^{\circ} \mathrm{C}$ for $10 \mathrm{~h}$. After drying, the dried pasta is packaged in plastic films to avoid moisture exchange.

\subsection{Chemical and Functional Analysis}

The analyzes performed on yam flour (A), durum wheat semolina (B) and soybean flour $(\mathrm{C})$ were chemical; those made on compound pasta were chemical and functional. For each flour sample and compound pasta test, we determined the following parameters: water content and ash after incineration according to the standard method developed by the Association of Official Analytical Chemists (AOAC); crude proteins $(\mathrm{N} \times 6.25)$, by the method of Kjeldahl, (1995). The acidity level of compound pasta was determined using the standard-metric method 947.05-AOAC [6] Revised by [5] used by [7]. The Optimal Cooking Time (TOC) was determined by the method used by [1] and the Swelling Index (GI) 
according to the equation of [8].

$$
\text { IG }(\%)=\frac{\text { Weight of cooked pasta }(\mathrm{TOC}+1 \mathrm{~min})-\text { weight of dry past }}{\text { Mass of dry pasta }}
$$

\subsection{Validation of Models and Study of Optimization}

After the model adjustment stage, iso-response curves are established over the entire experimental range. These curves represent plans for response surfaces, that is to say the graphic representation of the results (estimated model) in order to be able to draw optimums from them [9]. Then, to optimize the formulation of the compound flours in order to obtain the optimal culinary compound pasta while respecting the criteria imposed on the responses of interest: the Optimal Baking Time (OCD) and the Swelling Index (GI), we used the Desirability function. The desirability function is very useful when it is necessary to find the best compromise between several responses [10]. This function, which makes it possible to give an exact optimal mixture, varies between 0 and 1 . Indeed, the value 0 is assigned when the factors lead to an unacceptable response (undesirable) and that of 1 when the response represents the maximum performance desired for the factors considered [11].

\subsection{Formulation of $100 \%$ Durum Wheat Pasta and Optimal Compound Pasta}

The doughs were prepared according to the official [12] method, called the straight dough method with some modifications. The recipe for preparing pasta from $100 \%$ durum wheat semolina and flour made to obtain optimal pasta is presented in Table 2.

\subsection{Sensory Evaluation of Optimal Pasta}

Two tests were carried out to assess the sensory quality of our product:

The hedonic test was opted according to AFNOR standard V09-014 [13]. In this study, we followed an approach of realization of the sensory profiles and we were interested in the real analysis of the samples cooked on the basis of the list descriptors. A score on a scale of 1 to 6 is assigned for each characteristic. The samples are presented to each judge separately in a randomized order, each plate of which contained approximately $10 \mathrm{~g}$ of pasta. The criteria for judging cooked

Table 2. Formulation of $100 \%$ durum wheat pasta and optimal mixed pasta.

\begin{tabular}{ccc}
\hline Ingredients & Optimal compound pasta & 100\% durum wheat pasta \\
\hline Compound flour & $500 \mathrm{~g}$ & - \\
Semolina & - & $500 \mathrm{~g}$ \\
Salt & $10 \mathrm{~g}$ & $10 \mathrm{~g}$ \\
Distilled water & $350 \mathrm{ml}$ & $300 \mathrm{ml}$ \\
\hline
\end{tabular}

NB: The process for making pasta is the same as that indicated in the subtitle which deals with the effect of pastification. 
pasta were color, odor, taste, firmness and stickiness. The latter is appreciated visually by the ease of crumbling using a fork as well as in the mouth [14]. The different sensory parameters studied are: color, firmness, stickiness, odor and taste. The pasta samples were judged by 10 panelists made up of students from the agro-food department on a legend composed of Good, Average and not Good.

The placement test was also carried out by rank according to acceptability, without giving equality even if it seemed comparable. We used the table of critical values from the Friedman test to calculate the value of $\mathrm{T}$ according to the equation:

$$
T=\left(12 \sum R^{2} / b t(t+1)\right)-(3 b(t+1))
$$

$T$ : the value of the statistical test;

$R^{2}$ : the sum of the rows;

$b$ : the number of assessors;

$t$. number of samples.

To carry out the classification test, we used a third product (ordinary pasta sold on the Cebon brand market of $250 \mathrm{~g}$ ) which represents the witness for the classification to be effective.

\subsection{Statistical Analysis of Data}

The results obtained from the technological analyzes of flour, compound pasta and the sensory evaluation of optimal compound pasta were subjected to an analysis of variance (ANOVA), the significance of the statistical tests is determined at the threshold of $5 \%$ using Minitab version 17 . The means are compared with the Tukey test.

\section{Results and Discussion}

\subsection{Chemical Composition of Raw Materials}

Table 3 presents the chemical characteristics of the raw materials. The results obtained show that the water content varies from $10.29 \%$ to $12.29 \%$; that of ashes ranges from $0.91 \%$ to $5.74 \%$; proteins between $3.24 \%$ and $20.17 \%$. These results are comparable to those obtained by the authors cited in parenthesis [14] [15] [16] [17]. Water content is a crucial parameter in the storage of flour. Indeed, a

Table 3. Chemical composition of raw materials.

\begin{tabular}{cccc}
\hline Samples & Water content (\%) & Ash content (\%) & Protein content (\%) \\
\hline A & $10.29 \pm 5.18^{\mathrm{a}}$ & $3.5 \pm 1.60^{\mathrm{ab}}$ & $3.24 \pm 0.12^{\mathrm{C}}$ \\
B & $12.29 \pm 1.15^{\mathrm{a}}$ & $0.91 \pm 0.15^{\mathrm{b}}$ & $6.56 \pm 0.24^{\mathrm{b}}$ \\
C & $10.44 \pm 4.79^{\mathrm{a}}$ & $5.74 \pm 1.66^{\mathrm{a}}$ & $20.17 \pm 0.43^{\mathrm{a}}$ \\
\hline
\end{tabular}

A: yam flour; B: semolina; C: soy flour. The means \pm standard deviations followed by the same letter in the same column indicate that the differences are not significant; otherwise there is a significant difference ( $\mathrm{p}<$ $0.05, \mathrm{n}=3)$. Tukey test. 
water content of flour greater than $12 \%$ promotes the development of microorganisms. In our study, the water content of yam flour and soybeans is around $10 \%$, in contrast to that of durum wheat semolina is $12.29 \%$. The ash content is an indicator of the purity of the flour [18]; the results obtained are related to those of most tropical tubers [19]. The protein content of flour exerts a considerable influence on the viscoelastic properties of pasta and on the culinary quality of the finished product [9] [20]. In our case, the highest value was observed in soy flour $(\mathrm{C})$ which is much lower than that reported by [21], the rate of which is between $50 \%$ and $65 \%$ and the minimum value in yam flour (A).

\subsection{Chemical and Functional Parameters of Compound Pasta}

The results of analyzes of the chemical and functional parameters of the composite pasta are presented in Table 4.

We find that the water content of the series of 10 tests varies between $6.60 \%$ and $14.97 \%$. The maximum content was observed in test 10 , then the minimum content in test 1 . The water content is a crucial parameter in the storage of pasta, a high moisture content stimulates microbial activity which causes deterioration of product during storage. These results are comparable to those obtained by [1].

The iso-response curves shown in (Figure 1), generated by the adopted model (special quartic) indicate the interactions between the variables $(A, B, C)$ and humidity. The equation of the model is written in the following form:

$$
\begin{aligned}
\text { Water content }(\%)= & -0.1271 \mathrm{~A}+0.0367 \mathrm{~B}-0.1328 \mathrm{C}+0.0018 \mathrm{AB}+0.0003 \mathrm{AC} \\
& +0.012 \mathrm{BC}+8.97594 \times 10^{-11} \mathrm{AABC}-8.10330 \times 10^{-8} \mathrm{ABBC} \\
& +1.61670 * 10^{-8} \mathrm{ABCC}
\end{aligned}
$$

\section{The ash content:}

The ash content of the series of 10 tests varies between $0.97 \%$ and $1.67 \%$. The maximum value was observed in test 1 and 2 while the minimum content was

Table 4. Chemical and functional parameters of compound pasta.

\begin{tabular}{ccccccc}
\hline $\begin{array}{c}\text { Test } \\
\text { No. }\end{array}$ & $\begin{array}{c}\text { Water content } \\
(\%)\end{array}$ & $\begin{array}{c}\text { Ash content } \\
(\%)\end{array}$ & $\begin{array}{c}\text { Protein } \\
\text { content (\%) }\end{array}$ & $\begin{array}{c}\text { Acidity rate } \\
(\%)\end{array}$ & $\begin{array}{c}\text { Optimal } \\
\text { cooking time } \\
(\text { min) }\end{array}$ & $\begin{array}{c}\text { Swelling } \\
\text { index (\%) }\end{array}$ \\
\hline $\mathbf{1}$ & 6.60 & 1.67 & 7.17 & 2.57 & 18.00 & 92.54 \\
$\mathbf{2}$ & 7.43 & 1.67 & 7.15 & 1.55 & 16.19 & 77.65 \\
$\mathbf{3}$ & 12.74 & 1.55 & 10.10 & 2.31 & 19.02 & 66.18 \\
$\mathbf{4}$ & 7.40 & 0.97 & 9.13 & 3.60 & 20.00 & 107.12 \\
$\mathbf{5}$ & 10.32 & 1.43 & 11 & 2.90 & 18.04 & 59.70 \\
$\mathbf{6}$ & 7.61 & 1.26 & 12.10 & 3.20 & 15.00 & 63.65 \\
$\mathbf{7}$ & 10.23 & 1.02 & 10.20 & 1.78 & 16.30 & 73.21 \\
$\mathbf{8}$ & 9.76 & 1.30 & 8.25 & 2.00 & 17.22 & 67.09 \\
$\mathbf{9}$ & 11.58 & 1.07 & 10.90 & 1.35 & 15.60 & 63.63 \\
$\mathbf{1 0}$ & 14.97 & 1.58 & 8.81 & 2.07 & 17.02 & 65.58 \\
\hline
\end{tabular}


observed in test 4 . The ash rate varies according to the substitution rate and increases following the increase in yam flour and durum wheat semolina highly mineralized in the mixtures.

The ash content iso-response curves are presented in (Figure 2); and generated by the validated model (special quartic) show the interactions between the variables $(\mathrm{A}, \mathrm{B}, \mathrm{C})$ and the ash rate. The equation of the model is written in the following form.

$$
\begin{aligned}
\text { Ash content }= & -0.0122 \mathrm{~A}-0.0165 \mathrm{~B}-0.0162 \mathrm{C}+0.00021 \mathrm{AB} \\
& +0.00025 \mathrm{AC}+0.00012 \mathrm{BC}-7.249 \times 10^{-9} \mathrm{AABC} \\
& -5.948 \times 10^{-10} \mathrm{ABBC}-2.653 \times 10^{-9} \mathrm{ABCC}
\end{aligned}
$$

\section{iso-reponses curve of water content (quantities of components)}

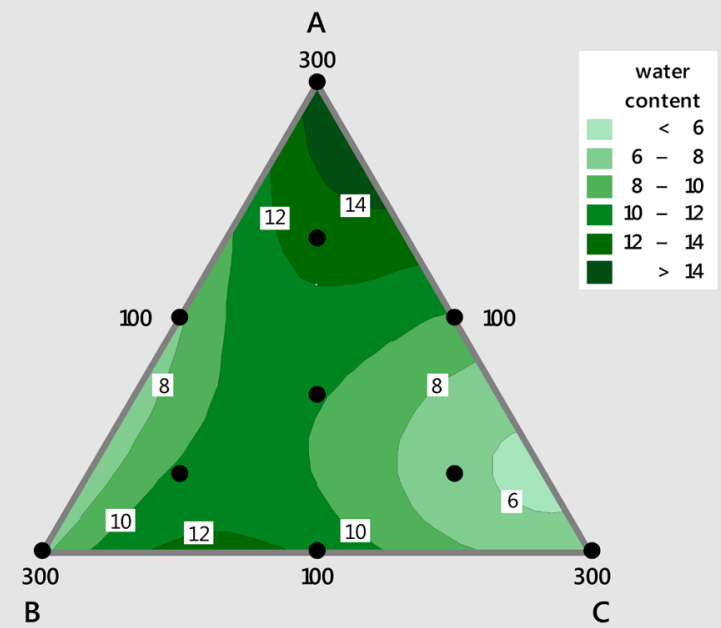

Figure 1. Iso-response curve of the water content.

\section{iso-reponses curve of ash content (quantities of components)}

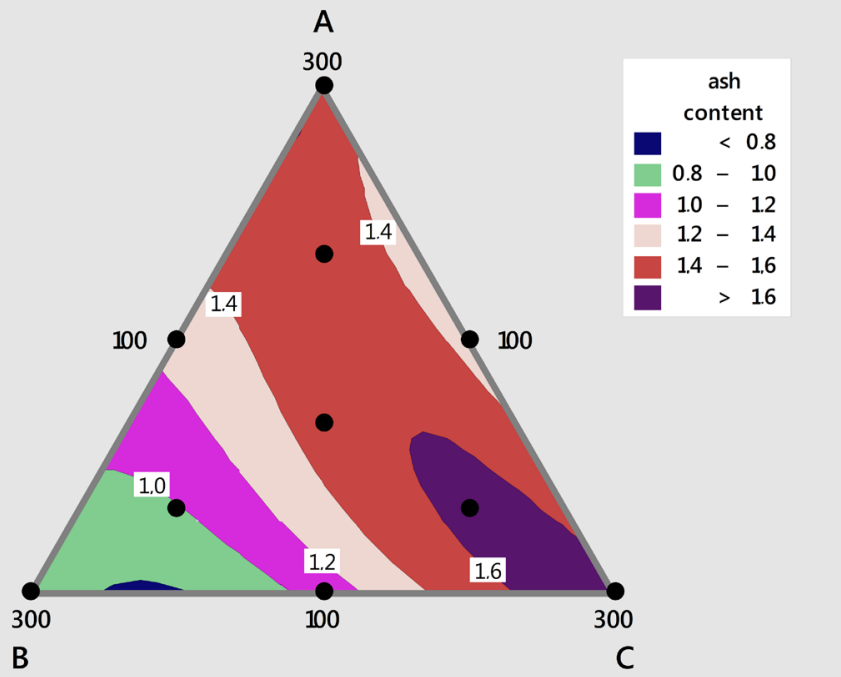

Figure 2. Iso-response curve of the ash content. 
The Protein content: The protein content of the series of 10 tests varies between $7.15 \%$ and $12.10 \%$. The maximum value was observed in test 6 which explains the dominance of the soy flour in the mixture, on the other hand the minimum value in test 2 . We note that the results obtained are comparable to those obtained by BRAHIMI Fatima, (2014), who worked on traditional spinach pasta with a protein content ranging from $9.2 \%$ to $12.11 \%$. Flour protein has a considerable influence on the viscoelastic properties of the pasta and on the culinary quality of the product. Finished [20] [22].

The iso-response curves generated by the validated model make it possible to visualize, as shown in (Figure 3), the interactions between the variables (A, B, C) and their effects on the protein content of compound pasta. The equation of the model is written in the following form:

$$
\begin{aligned}
\text { Protein content } & =0.082 \mathrm{~A}+0.169 \mathrm{~B}+0.15 \mathrm{C}-7.814 \times 10^{-4} \mathrm{AB} \\
& -0.0015 \mathrm{AC}-8.899 \times 10^{-4} \mathrm{BC}+3.385 \times 10^{-8} \mathrm{AABC} \\
& -1.6008 \times 10^{-8} \mathrm{ABBC}+2.960 \times 10^{-8} \mathrm{ABCC}
\end{aligned}
$$

\section{The acidity rate:}

The acidity level of the 10 test series varies between $1.35 \%$ and $3.60 \%$. The maximum value was observed in test 4 while the minimum value in test 9 . The iso-response curves (Figure 4) plotted from the determined and validated model illustrate the effects of the variables $(A, B, C)$ on the acidity level of the compound pasta. The equation of the model is written in the following form:

$$
\begin{aligned}
\text { Acidity level }= & 0.0671 \mathrm{~A}+0.0459 \mathrm{~B}+0.0550 \mathrm{C}-4.839 \times 10^{-4} \mathrm{AB} \\
& -6.057 \times 10^{-4} \mathrm{AC}-6.969 \times 10^{-4} \mathrm{BC}+2.544 \times 10^{-9} \mathrm{AABC} \\
& +1.350 \times 10^{-8} \mathrm{ABBC}+1.604 \times 10^{-8} \mathrm{ABCC}
\end{aligned}
$$

\section{The optimum cooking time:}

The optimum cooking time (TOC) of the different pastas, shown in Table 4,

iso-reponses curve of protein content (quantities of components)

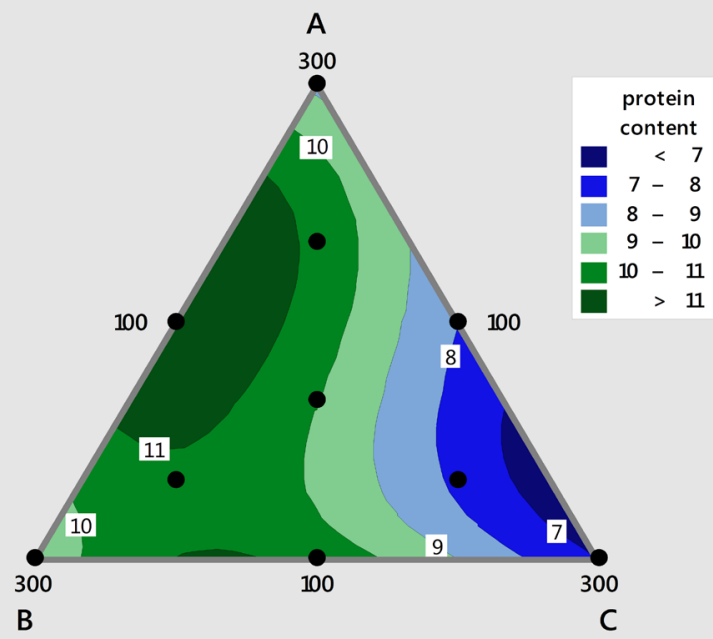

Figure 3. Iso-response curves of protein content. 
iso-reponses curve of the acidity rate (quantities of components)

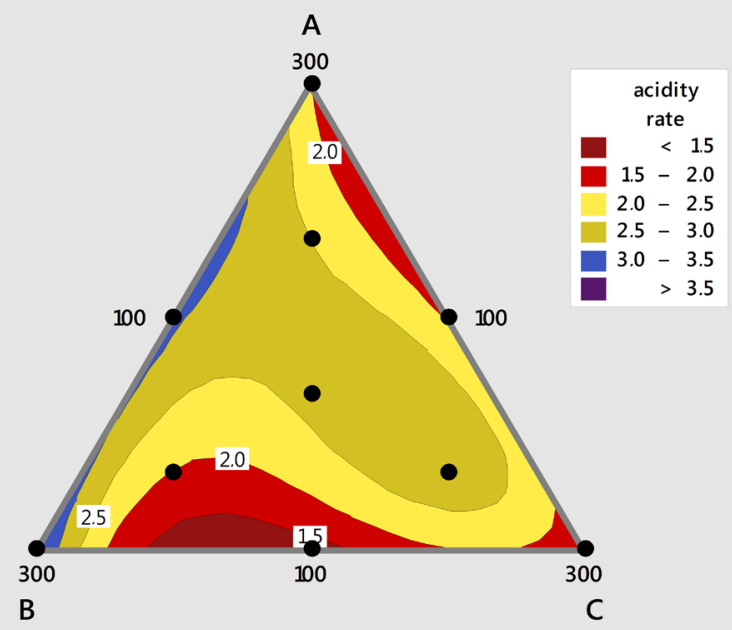

Figure 4. Iso-response curve of the acidity rate.

iso-reponses curve of optimum cooking time (quantities of components)
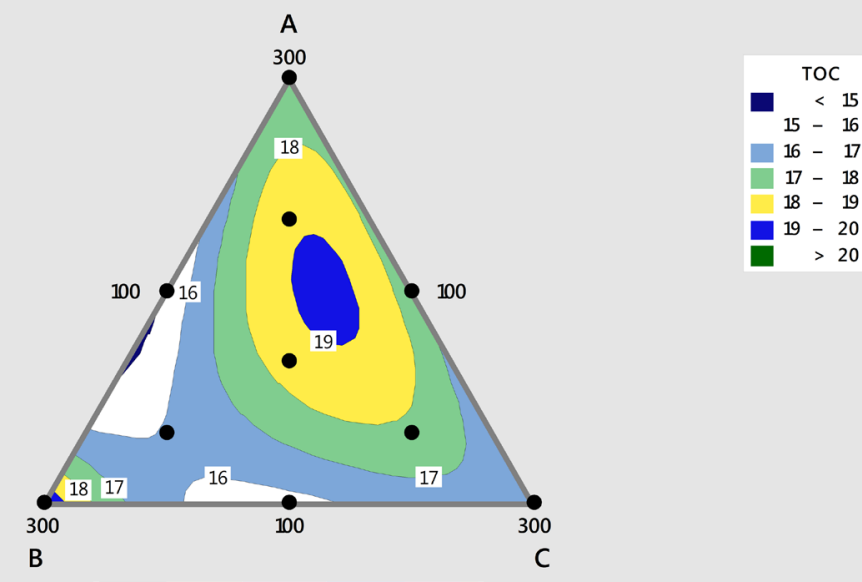

Figure 5. TOC iso-response curve.

was used to assess the swelling index of the pasta produced.

The optimum cooking time of the series of 10 tests varies between $15 \mathrm{~min}$ and $20 \mathrm{~min}$, the maximum time was observed in test 4 consisting of the same quantity $(166.67 \mathrm{~g})$ for all the components of the mixture $(\mathrm{A}+\mathrm{B}+\mathrm{C})$ while the minimum in test 6 . The iso-response curves (Figure 5 ) generated by the verified model (special quartic) represent the interactions between the variables (A, B, C) and the optimal time of cooking. The equation of the model is written in the following form:

$$
\begin{aligned}
\mathrm{TOC}= & 0.132 \mathrm{~A}+0.121 \mathrm{~B}+0.049 \mathrm{C}-7.290 \times 10^{-4} \mathrm{AB} \\
& -8.143 \times 10^{-4} \mathrm{AC}-9.884 \times 10^{-4} \mathrm{BC}+5.562 \times 10^{-10} \mathrm{AABC} \\
& +1.466 \times 10^{-8} \mathrm{ABBC}+3.500 \times 10^{-8} \mathrm{ABCC}
\end{aligned}
$$

\section{The swelling index:}

The swelling index or the cooking weight in the mixes is between $59.70 \%$ and 
iso-reponses curve of the swelling index (quantities of components)

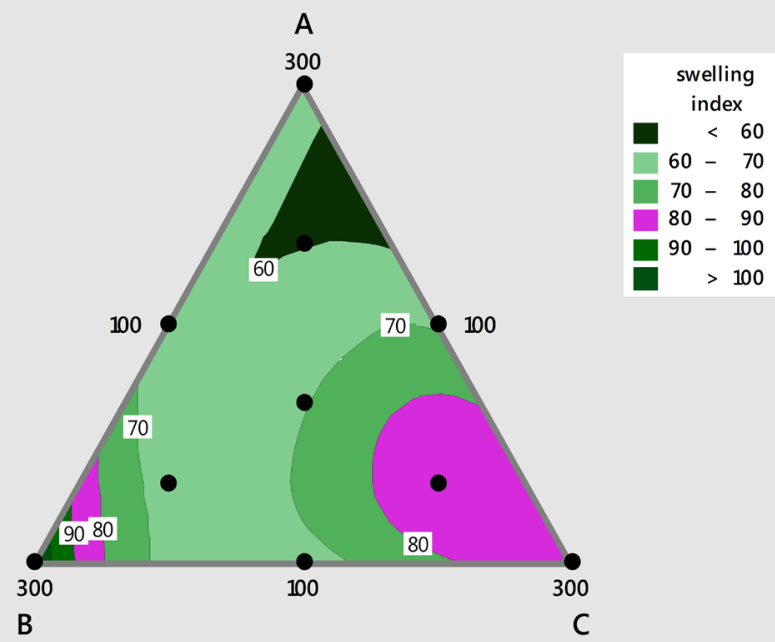

Figure 6. Iso-response curve of the swelling index.

$107.12 \%$. The maximum index was observed in test 4 , the minimum was recorded in test 5 . The iso-response curves generated by the model used (Special Quartic) indicate in (Figure 6), the interactions between the variables (A, B, C) and the swelling index in the mixtures. The equation of the model is written in the following form:

$$
\begin{aligned}
\mathrm{GI}= & 1.137 \mathrm{~A}+0.319 \mathrm{~B}+1.0573 \mathrm{C}-0.0110 \mathrm{AB}-0.00531 \mathrm{AC}-0.0102 \mathrm{BC} \\
& +4.269 \times 10^{-8} \mathrm{AABC}+4.694 \times 10^{-7} \mathrm{ABBC}+2.739 \times 10^{-8} \mathrm{ABCC}
\end{aligned}
$$

\subsection{Comparative Study of the Chemical and Functional Parameters of Compound Pasta}

The analysis of variance (ANOVA) of the suggested models representing the results of the centered mixing plans used are shown in Table 5 and Table 6 respectively. The significance level of the sources of variances of the models was defined at 0.05 .

This analysis, presented in the tables, suggests models relating the responses (water content, ash, proteins, acidity rate, optimal cooking time and swelling index) to the flour variables, respectively: yam (A), durum wheat semolina (B) and soy flour (C). Statistical tests (test F) from these tables indicate that the main regression effects are not significant with a p-value probability greater than 0.05 .

\subsection{Validity of mathematical models}

All the necessary characteristics for adjusting the models obtained are shown in Table 7. The coefficient of determination $\mathrm{R}^{2}$ defines the ratio of the variation in responses which is explained by the model. The closer the value of $\mathrm{R}^{2}$ is to 1 , the better the fit of the model. The $\mathrm{R}^{2}$-Adjusted is a correction made to the value of $\mathrm{R}^{2}$ as a function of the number of degrees of freedom. 
Table 5. Analysis of variance of the chemical parameters of compound pasta.

\begin{tabular}{|c|c|c|c|c|}
\hline Source & SC & $\mathrm{DL}$ & $\mathrm{CM}$ & Value of $F$ \\
\hline \multicolumn{5}{|c|}{ Water content } \\
\hline Regression & 64.9945 & 8 & 8.1243 & 18.68 \\
\hline Linear & 18.8994 & 2 & 9.9097 & 22.78 \\
\hline Quadratic & 9.3558 & 3 & 12.6556 & 29.09 \\
\hline Special Quartic & 36.7393 & 3 & 12.2464 & 28.15 \\
\hline \multicolumn{5}{|c|}{ Ash content } \\
\hline Regression & 0.589305 & 8 & 0.073663 & 1.32 \\
\hline Linear & 0.139609 & 2 & 0.006257 & 0.11 \\
\hline Quadratic & 0.133218 & 3 & 0.147678 & 2.64 \\
\hline Special Quartic & 0.316479 & 3 & 0.105493 & 1.88 \\
\hline \multicolumn{5}{|c|}{ Protein content } \\
\hline Regression & 24.3029 & 8 & 3.03786 & 4.74 \\
\hline Linear & 3.1796 & 2 & 2.09641 & 3.27 \\
\hline Quadratic & 3.1796 & 3 & 4.69093 & 7.32 \\
\hline Special Quartic & 12.1933 & 3 & 4.06443 & 6.35 \\
\hline \multicolumn{5}{|c|}{ Acidity rate } \\
\hline Regression & 4.30923 & 8 & 0.53865 & 1.1 \\
\hline Linear & 1.5913 & 2 & 0.12001 & 0.24 \\
\hline Quadratic & 0.37892 & 3 & 0.78831 & 1.6 \\
\hline Special Quartic & 2.33901 & 3 & 0.77967 & 1.59 \\
\hline
\end{tabular}

SC: Sum of Squares, DL: Degree of Freedom, CM: Average Square, Value of F: Fisher Variance.

Table 6. Analysis of variance on a functional property of compound pasta.

\begin{tabular}{|c|c|c|c|c|}
\hline Source & $\mathrm{SC}$ & $\mathrm{DL}$ & $\mathrm{CM}$ & Value of $F$ \\
\hline \multicolumn{5}{|c|}{ TOC } \\
\hline Regression & 19.5134 & 8 & 2.43917 & 1.09 \\
\hline Linear & 8.7026 & 2 & 2.21272 & 0.99 \\
\hline Quadratic & 3.1952 & 3 & 1.47922 & 0.66 \\
\hline Special Quartic & 7.61548 & 3 & 0.582 & 1.14 \\
\hline \multicolumn{5}{|c|}{ IG } \\
\hline Regression & 1632.72 & 8 & 204.09 & 0.49 \\
\hline Linear & 63.86 & 2 & 217.28 & 0.52 \\
\hline Quadratic & 381.95 & 3 & 312.81 & 0.75 \\
\hline Special Quartic & 1186.91 & 3 & 395.64 & 0.94 \\
\hline
\end{tabular}

SC: Sum of Squares, DLL: Degree of freedom, CM: Average Square, Value of F: Fisher variance. 
Table 7. Summary of the adjustment of the mathematical models adopted for the responses chemical and functional parameters of the compound pasta.

\begin{tabular}{ccccccc}
\hline Settings & $\begin{array}{c}\text { Water } \\
\text { content }\end{array}$ & Ashes & Protein & Acidity rate & TOC & IG \\
\hline Average & $9.86^{\mathrm{c}} \pm 2.69$ & $1.35^{\mathrm{d}} \pm 0.26$ & $9.48^{\mathrm{c}} \pm 1.66$ & $2.33^{\mathrm{d}} \pm 0.73$ & $17.23^{\mathrm{b}} \pm 1.55$ & $73.64^{\mathrm{a}} \pm 15.10$ \\
$\mathrm{R}^{2}$ & 0.9934 & 0.9132 & 0.9743 & 0.8977 & 0.8973 & 0.7956 \\
$\mathrm{R}^{2}$-Adjusted & 0.9402 & 0.2189 & 0.7689 & 0.0797 & 0.0761 & 0.00 \\
\hline
\end{tabular}

Statistical analysis of the data shows that the $\mathrm{R}^{2}$ values range from 0.7936 to 0.9934. Indeed, the highest value of $R^{2}(0.9934)$ was obtained by the special quartic model which best simulates the water content, followed by the $\mathrm{R}^{2}$ protein content (0.9743) of the compound pasta. The lowest value was obtained by the same $\mathrm{R}^{2}$ model (0.7956); which indicates that the mathematical model adopted did not give a good adjustment of the swelling index of the compound pasta.

\subsection{Optimization of Responses}

Average \pm : standard deviation, $\mathrm{R}^{2}$ : Correlation coefficient, $\mathrm{R}^{2}$-Adjusted: adjusted correlation coefficient, TOC: Optimal cooking time, GI: Swelling index and the index of swelling. The results obtained made it possible to locate the lower and upper limits according to the target as shown in Table 8.

Indeed, the multi-criteria analysis using the desirability function made it possible to determine the compound flour with optimal culinary responses from the previously established model. The constraints imposed were: TOC and IG. The results show that the desirability which amounts to 0.98 is close to 1 when the following optimum multi-criteria conditions are achieved: Yam flour $(\mathrm{A})=102.020$ or $20.40 \%$, durum wheat semolina $(B)=273,982$ or $55.19 \%$; Soy flour $(C)=$ 121.998 or $24.39 \%$. Hence the answer optimization diagram (Figure 7).

\subsection{Sensory evaluation}

\section{Hedonic test}

The hedonic test results for optimal compound doughs are shown in Figure 8.

From the graph, it appears that the sensory parameters are widely appreciated by the tasters. This proves that our pasta is of good quality from an organoleptic point of view. For all the different parameters studied, the taste of the compound pasta represents the most appreciated parameter with a percentage of around $70 \%$ to which is added the color which was appreciated at $60 \%$. The firmness and the stickiness were appreciated in an acceptable manner, however the level of appreciation of the odor parameter was not good.

Placement test

The results of the benchmarking obtained on the three samples made it possible to classify these samples according to the level of preference. It follows that the control doughs are classified first makes followed by the optimal compound 
Table 8. lower and upper limits according to the target.

\begin{tabular}{ccccc}
\hline Settings & Goals & Lower & Target & Superior \\
\hline TOC & Target & 15 & 18 & 20 \\
IG & Target & 50 & 80 & 100 \\
\hline
\end{tabular}

GI: Swelling Index; TOC: Optimal Cooking Time.

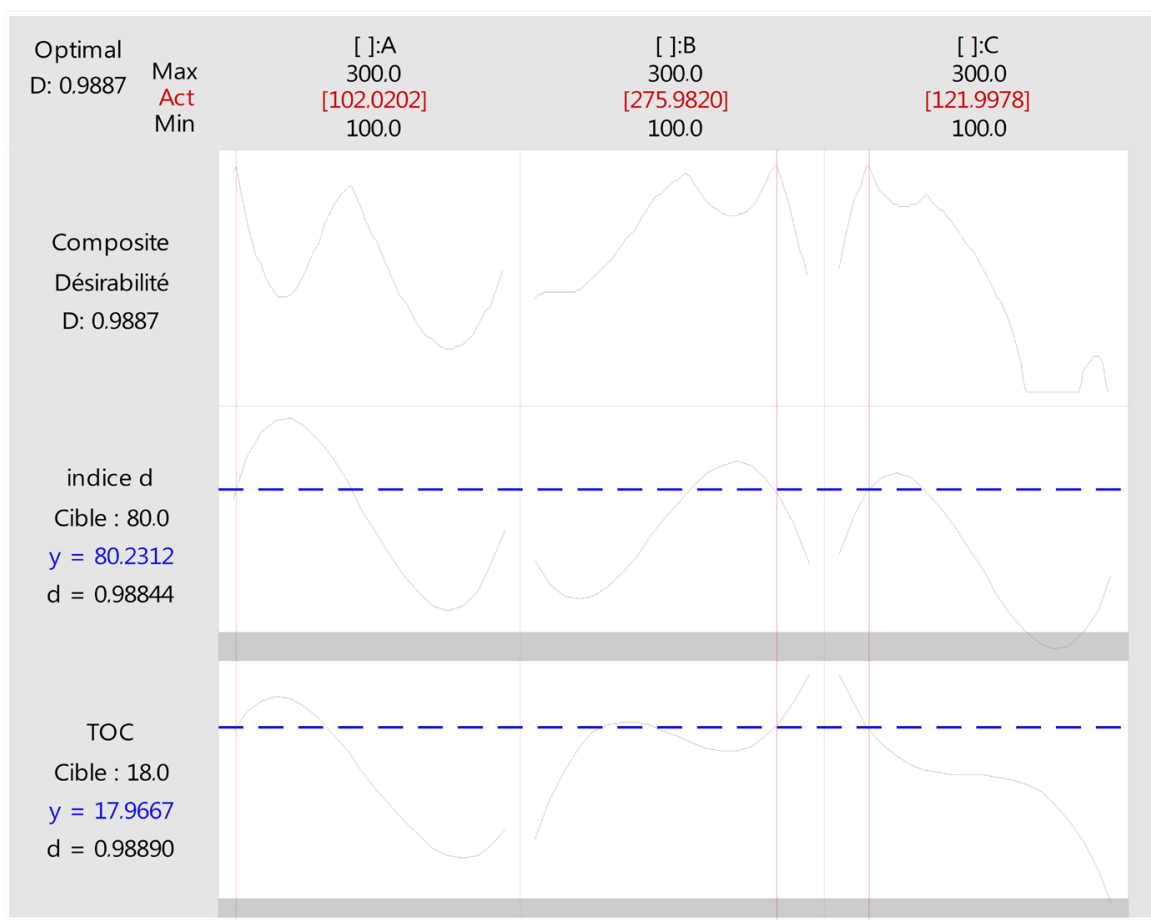

d: individual desirability evaluating to what extent the parameters optimize a single response; $\mathrm{D}$ : Composite desirability evaluating to what extent the parameters globally optimize a set of responses.

Figure 7. Optimization of responses diagram.

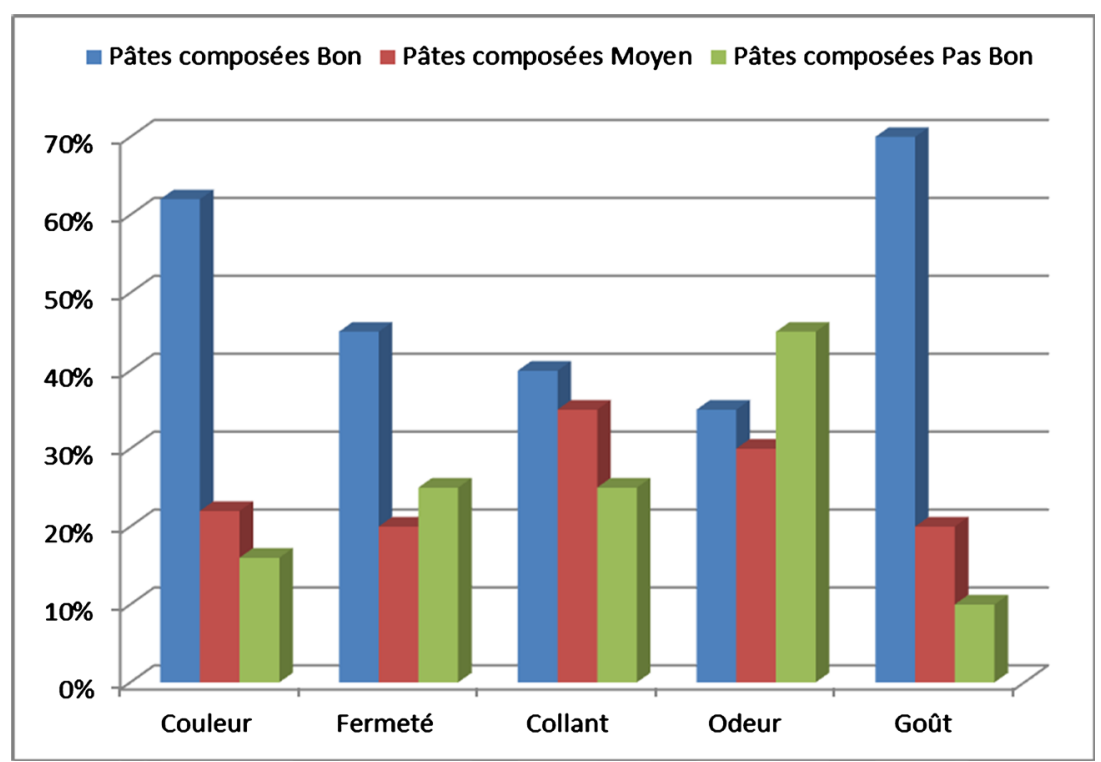

Figure 8. Assessment of the sensory parameters of optimal compound pasta. 
pasta and finally the $100 \%$ durum wheat pasta.

\section{Conclusion}

The use of the experimental design method has allowed us to develop models with a good level of acceptability for estimating the chemical and culinary parameters of compound pasta (yam, durum wheat and soy). The coefficients of determination $\mathrm{R}^{2}$ values confirmed the high degree of correlation of the mathematical model used (special quartic model) according to the observed values. Optimization has shown that $20.40 \%$ yam flour $(102.020 \mathrm{~g})$; $55.19 \%$ of durum wheat semolina (i.e. $275.982 \mathrm{~g}$ ) and $24.39 \%$ of soy flour (i.e. $121.998 \mathrm{~g}$ ) could be combined without noticeable impairment of the sensory characteristics of the pasta. The acceptability of our products through sensory analyzes has proven to be favorable, since many people have indeed appreciated the taste qualities of our products.

\section{Conflicts of Interest}

The authors declare no conflicts of interest regarding the publication of this paper.

\section{References}

[1] Ahlem D. (2013) Technological and Culinary Skills of Pasta Enriched with Wheat Germ. Memory of Constantine University 1, Constantine, 148 p.

[2] Lydia, S. and Yasmina, M. (2017) Enrichment of Pasta with Moringa Leaf Powder (Oleifera). Dissertation, Universite Abderrahmane Mira, Bejaia, 87 p.

[3] Fatima, B. (2014) Traditional Algerian Spinach Paste "Mkartfa Type". Memory of the Constantine University 1, Constantine, 123 p. http://docplayer.fr/75840293

[4] Salima, B. (2010) Contribution to the Study of the Improvement of the Nutritional Quality of the Mixture of Common Wheat Flour with Corn Flour. Memory of the University of Abu Bakr Belkaido “Tlemcen”, 84 p.

[5] AOAC: Reviewed by William H., George W. and Latimer J.R. (2011) The Scientific Association Dedicated to Analytical Excellence: Official Methods of Analysis. Current through Revision 4. https://www.aoac.org/official-methods-of-analysis-21st

[6] Association of Official Analytical Chemists (1990) The Official Methods of Analysis of the Association of Official Analytical Chemists. 15th Edition, Vol. 1, Association of Official Analytical Chemists, Arlington.

[7] Pınarlı, İ., İbanoğlu, Ş., and Öner, M.D. (2004) Effect of Storage on the Selected Properties of Macaroni Enriched with Wheat Germ. Journal of Food Engineering, 64, 249-256. https://doi.org/10.1016/j.jfoodeng.2003.10.005

[8] Petitot, M., Brossard, C., Barrona, C., Larre, C., Morel, M.H. and Micard, V. (2009) Modification of Pasta Structure Induced by High Drying Temperatures. Effects on the in Vitro Digestibility of Protein and Starch Fractions and the Potential Allergenicity of Protein Hydrolysates. Food Chemistry, 116, 401-412. https://doi.org/10.1016/j.foodchem.2009.01.001

[9] Fadil, M., Farah, A., Ihssane, B., Haloui, T. and Rachiq, S. (2015) Optimization of Parameters Influencing the Hydrodistillation of Rosmarinus officinalis L. by Re- 
sponse Surface Methodology. Flight, 6, 2346-2357.

[10] Goupy, J. (2005) Practice the Experimental Designs. Dunod Edition, Paris, 551 p.

[11] Mourabet, M. (2014) Modeling and Optimization of the Adsorption of Fluoride ions on Calcium Phosphates. Doctoral Thesis, Faculty of Sciences, Kenitra. 156 p.

[12] American Association of Cereal Chemists (1995) Approved Methods of the AACC. 9th Edition, American Association of Cereal Chemists, St. Paul.

[13] Association Française de Normalisation (1995) Collection of Standards-Quality Control of Food Products: Sensory Analysis. 5th Edition, Association Française de Normalisation, Paris, $400 \mathrm{p}$. https://www.boutique.afnor.org/norme/iso-10545-141995

[14] Ganongo-Po, F.B., Matos, L., Kimbonguila, A., Ndangui, C.B., Nzikou, J.M. and Scher, J. (2018) Sieving Effect on the Physicochemical and Functional Properties of Taro (Colocasia esculenta.) Flour. Advance Journal of Food Science and Technology, 14, 42-49. http://dx.doi.org/10.19026/ajfst.14.5830

[15] Abecassis, J. (1987) Durum Wheat Test Milling: Industrial Research and Applications. $16 \mathrm{p}$.

[16] Kouadio Chiado Julie, N., Dan Chépo, G., Konan Kouassi, H., Assoi Yapi Désiré, P., Kouamé Lucien, P. and Kamenan, A. (2017) Biochemical and Functional Properties of Yam Flour during the Post-Harvest Conservation of Dioscorea alata Cultivar “Azaguié". Current Journal of Applied Science and Technology, 21, 1-10. https://doi.org/10.9734/CJAST/2017/32404

[17] Coulibaly, S., Maniga, W., Adou Tana, A., Nemlin, G.J. and Kouame, P. (2017) Physicochemical Properties of Pretreated Flours and Organoleptic Characteristics of Couscous of Four Varieties of Yams (Dioscorea cayenensis rotundata) Grown in Côte d'Ivoire. International Journal of Pure \& Applied Bioscience, 6, 747-761. http://dx.doi.org/10.18782/2320-7051.1272

[18] Ndangui, C.B. (2015) Production and Characterization of Sweet Potato Flour (Ipomoeabatatas. Lam): Optimization of Bread-Making Technology. Ph.D. These, Universite de Lorraine and Universite Marien Ngouabi, Grand Est, 91-104. https://hal.univ-lorraine.fr/tel-01751669

[19] Benkadri, S. (2010) Contribution to the Diversification of Food for Celiac Children Making Gluten-Free Flour and Biscuits. Memory of Magister. Universite Mentouri de Constantine, Algeria, 46.

[20] Feillet, P. (2000) The Grain of Wheat: Composition and Use. Ed. INRA, 308 p.

[21] Codex stan 175. (1989) Codex General Standard for Soy Protein Materials. 3 p.

[22] Petitot, M., Boyer, L., Minier, C. and Micard, V. (2010) Fortification of Pasta with Split pea and Faba Bean Flours: Pasta Processing and Quality Evaluation. Food Research International, 43, 634-641. https://doi.org/10.1016/j.foodres.2009.07.020 